Vol. 6, No. 1, 2020

\author{
Alper Uysal ${ }^{1}$, Eshreb Dzhemilov ${ }^{2}$, Ruslan Dzhemalyadinov ${ }^{3}$ \\ 1. Department of Mechanical Engineering, Yildiz Technical University, Turkey, Istanbul, Besiktas, 34349, \\ E-mail: auysal@yildiz.edu.tr, ORCID 0000-0002-5513-4431 \\ 2. Department of Mechanical Engineering, Crimean Engineering and Pedagogical University \\ named after Fevzi Yakubov, Republic of Crimea, Simferopol, Uchebnyy side st., 8, \\ E-mail: eshrebdzhemilov@gmail.com, ORCID 0000-0002-2770-5604 \\ 3. Department of Mechanical Engineering, Crimean Engineering and Pedagogical University \\ named after Fevzi Yakubov, Republic of Crimea, Simferopol, Uchebnyy side st., 8, \\ E-mail: rus.dzhemalyadino@gmail.com, ORCID 0000-0003-3319-3542
}

\title{
EFFECT OF MWCNT ON SURFACE ROUGHNESS AND BURR HEIGHT IN MQL MILLING OF AISI 430 FERRITIC STAINLESS STEEL
}

Received: March 12, 2020 / Revised: June 8, 2020 / Accepted: July 31, 2020

\section{(C) Uysal A., Dzhemilov E., Dzhemalyadinov R., 2020}

\begin{abstract}
Stainless steel materials have been used in many fields such as automotive, aviation, medical industries, etc. In addition, these materials are classified as difficult-to-cut materials due to low thermal conductivity and work-hardening tendency. Therefore, studies on machining of these materials have been performed in order to understand the basic of the process. In this study, surface roughness and burr height were investigated in MQL (Minimum Quantity Lubrication) milling of AISI 430 ferritic stainless steel. In MQL milling, commercial vegetable cutting fluid and MWCNT (Multi Walled Carbon Nanotube) reinforced vegetable cutting fluid were used. The milling experiments were also conducted under dry condition. In the experiments, uncoated WC (Tungsten Carbide) and TiN (Titanium Nitride) coated WC cutting inserts were used. Based on the experimental results, MQL method reduced the surface roughness and burr heights and better surfaces were obtained by using nanofluids in MQL method.
\end{abstract}

Keywords: surface roughness, burr height, milling, MQL, MWCNT, ferritic stainless steel.

\section{Introduction}

High quality and near-net-shape products could be obtained by modern manufacturing methods. However, the proportion of machining is still large among the manufacturing methods, especially for difficult-to-cut materials such as stainless steels, Titanium alloys, Nickel alloys, etc. Products from corrosion-resistant steels find the application areas in the chemical, medical and other related industries, where the requirements for the quality of parts are very significant.

\section{Problem Statement}

The processing of stainless steels is the main issue for many studies. In milling of stainless steel materials, various cutting tool failures such as flank wear, crater wear, cracks, chipping, etc. can be observed because of their work hardening tendency and low thermal conductivity. For this reason, this paper aims to develop some coolants and coatings to reduce these formations.

\section{Review of Modern Information Sources on the Subject of the Paper}

In the study of Sutar and Gujar [1], the influence of cutting parameters and the usage of various types of technical fluids on the surface roughness were investigated. The research study showed that Taguchi design method allowed optimizing the surface quality and it was also specified that the significant contribution of the technological environment to the parameters of the cutting process. Yao et al. [2] investigated the milling process of high-strength 3J33B maraging steel and presented that the increase in specific cutting energy contributed to an improvement in surface quality and an increase in the size of the 


\section{Effect of MWCNT on surface roughness and burr height in MQL milling of AISI 430 ferritic ...}

upper burrs. Meixia et al. [3] studied the influence of cutting parameters and directions on the shape and size of the resulting burrs during micro milling of $310 \mathrm{~S}$. Results showed that the depth of the cut affected the shape of the resulting burrs.

The problem of increasing productivity while maintaining the required product quality is often solved through the use and proper selection of cutting fluids. The compositions of cutting fluids used in production are made from oil products, but the environmental problem has been attracting more attention due to containing organic compounds of nitrogen, chlorine, phosphorus and sulfur. The decomposition and interaction products may have carcinogenic and mutagenic properties and may cause damage ecology and health of workers [4]. This aspect contributes to the development and implementation of advanced technologies aimed at improving the quality of metal machining and reducing the negative impact on the environment. Ogedengbe1 at al. [5] compared the effects of vegetable oil and industrial emulsion on the turning process of stainless steel and specified that natural oils had higher lubricating properties which affected the reduction of surface roughness. Kumar et al. [6] studied the effect of vegetable oils with the addition of extreme pressure additives on cutting force, temperature, tool wear and surface roughness during turning of AISI 1040 steel.

Results showed that vegetable oils with the addition of extreme pressure additives reduced the cutting forces and improved the surface quality.

The rare use of vegetable oils as an alternative to traditionally used production compounds is explained by the high cost of raw materials and the polymerization of most groups of vegetable oils. This problem can be solved through the use of MQL (Minimum Quantity Lubrication) which reduces the lubricant consumption by supplying it in the form of an aerosol [7].

Research studies showed that MQL technology had a positive effect on improving surface quality, improving tool life and reducing cutting forces compared to flood cooling [8]-[11].

\section{Objectives and Problems of Research}

Therefore, in this experimental study, the effect of commercial vegetable cutting fluid and MWCNT (Multi Walled Carbon Nanotube) reinforced vegetable cutting fluid on the surface roughness and burr height during MQL milling of AISI 430 stainless steel with uncoated and TiN coated WC tools were investigated.

\section{Main Material Presentation}

In the experiments, AISI 430 ferritic stainless steel parts were selected as workpiece material and its chemical composition was given in Table 1 . The dimensions of the workpieces were $400 \times 250 \times 6 \mathrm{~mm}$.

Table 1

The chemical composition of AISI 430 Ferritic Stainless Steel

\begin{tabular}{|c|c|c|c|c|c|c|}
\hline $\mathrm{C} \%$ & $\mathrm{Mn} \%$ & $\mathrm{~S} \%$ & $\mathrm{P} \%$ & $\mathrm{Si} \%$ & $\mathrm{Ni} \%$ & $\mathrm{Cr} \%$ \\
\hline 0.052 & 0.69 & 0.002 & 0.029 & 0.67 & 0.26 & 16.54 \\
\hline
\end{tabular}

During milling experiments, uncoated WC (Tungsten Carbide) and TiN (Titanium Nitride) coated WC cutting inserts were mechanically mounted on the $32 \mathrm{~mm}$ diameter tool holder and the experiments were performed by using a CNC machining center. The milling parameters and conditions were given in Table 2 .

The milling experiments were carried out under dry, MQL with commercial vegetable cutting fluid, and MQL with nanofluid conditions as seen in Fig. 1. A commercial vegetable cutting fluid was used. In order to obtain nanofluid, MWCNT (Multi Walled Carbon Nanotube) particles were added at weight fractions of $0.2 \% \mathrm{wt}$ to the vegetable cutting fluid. Firstly, MWCNT particles were dried for 2 hours at $120^{\circ} \mathrm{C}$ in a drying oven. Then, dried nano particles were added to the vegetable cutting fluid with sodium dodecyl sulfate and the nanofluids were prepared by a digital homogenizer.

Surface roughness values of the machined surfaces were measured using Time TR200 surface roughness tester. Five measurements were performed and arithmetic means were determined. SOIF XLB45-B3 digital stereo microscope was used to view and measure the burr heights. 
Milling parameters and conditions

\begin{tabular}{|c|c|c|c|c|c|}
\hline $\begin{array}{c}\text { Cutting } \\
\text { Condition } \\
\end{array}$ & $\begin{array}{l}\text { MQL Flow } \\
\text { Rate (ml/h) }\end{array}$ & Cutting Tool & $\begin{array}{c}\text { Cutting Speed } \\
(\mathrm{m} / \mathrm{min})\end{array}$ & Feed $(\mathrm{mm} / \mathrm{rev})$ & $\begin{array}{l}\text { Depth of } \\
\text { Cut (mm) } \\
\end{array}$ \\
\hline Dry & - & Uncoated WC & \multirow{10}{*}{100} & \multirow{10}{*}{0.18} & \multirow{10}{*}{0.5} \\
\hline Dry & - & TiN coated WC & & & \\
\hline MQL & 20 & Uncoated WC & & & \\
\hline MQL & 40 & Uncoated WC & & & \\
\hline MQL & 20 & TiN coated WC & & & \\
\hline MQL & 40 & TiN coated WC & & & \\
\hline Nano MQL & 20 & Uncoated WC & & & \\
\hline Nano MQL & 40 & Uncoated WC & & & \\
\hline Nano MQL & 20 & TiN coated WC & & & \\
\hline Nano MQL & 40 & TiN coated WC & & & \\
\hline
\end{tabular}

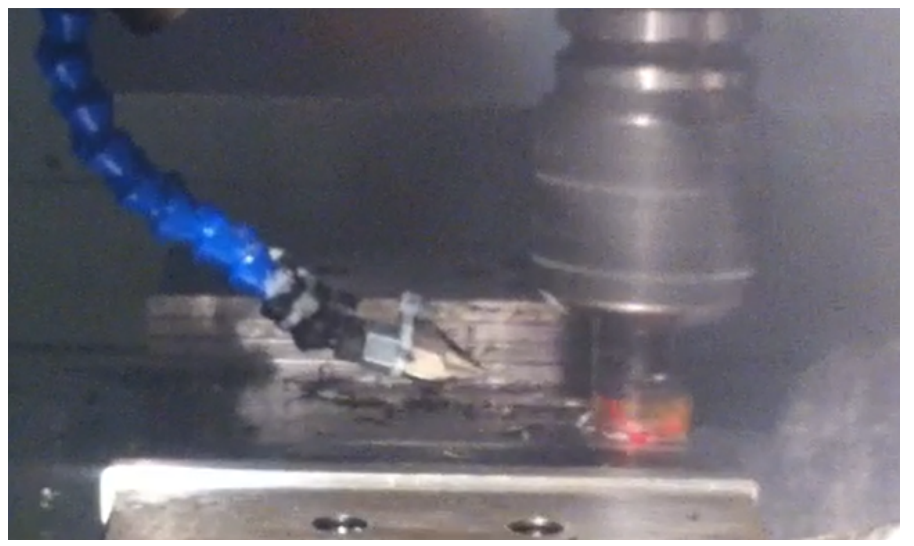

Fig. 1. Pulverizing the cutting fluid to the cutting area during MQL milling

By applying MQL method, reductions in surface roughness and burr heights were obtained as compared to dry milling due to effectively reaching of the cutting fluid into the cutting zone. As seen in Figs. 2-5, better surface roughness and smaller burr height in nano MQL method were observed than those in dry and MQL operations because of lubrication and heat removal effects of MWCNT particles in nanofluid. In addition, surface roughness and burr height decreased with increasing the MQL flow rate. Because, the amount of pulverizing cutting fluid to the cutting zone increased and so better surface quality could be obtained. Besides, lower surface roughness and smaller burr height were measured with TiN coated WC tools than those measured with uncoated WC tools (Figs. 2-5) due to having low friction coefficient of TiN coating.

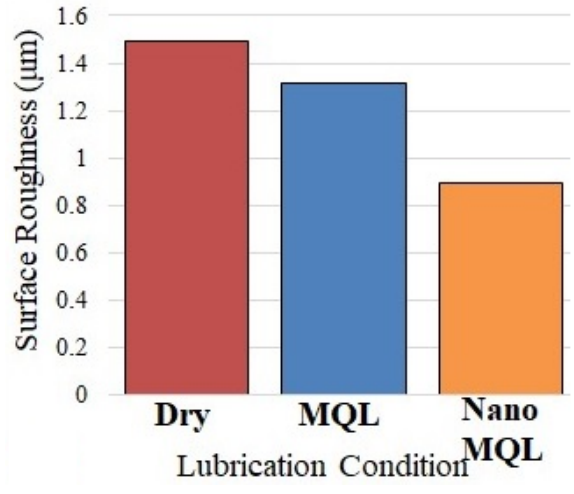

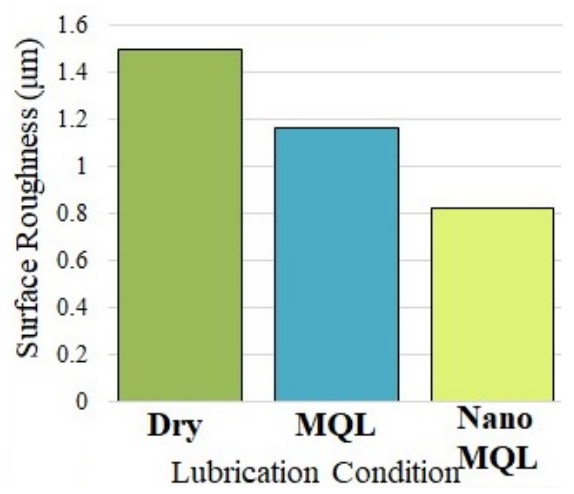

b

Fig. 2. The variation of surface roughness based on lubrication condition in milling with uncoated WC cutting tool: a - MQL flow rate of $20 \mathrm{ml} / \mathrm{h} ; \mathrm{b}-\mathrm{MQL}$ flow rate of $40 \mathrm{ml} / \mathrm{h}$ 


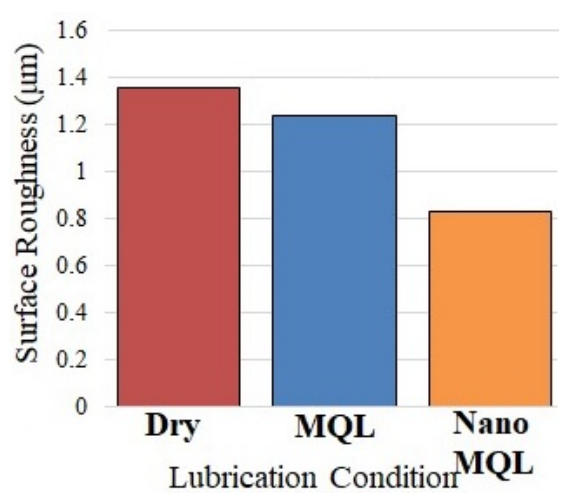

a

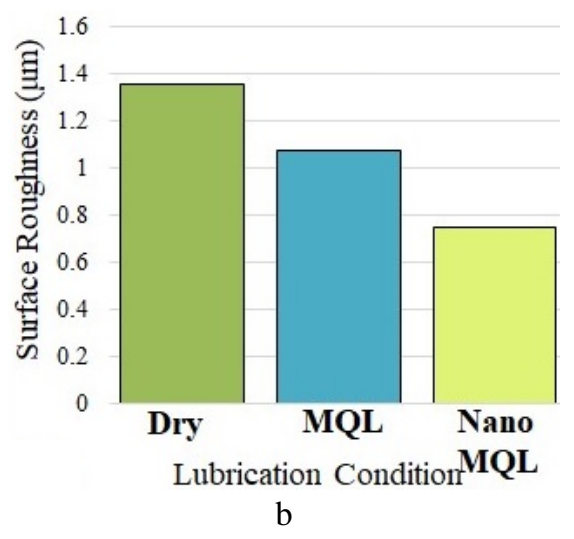

Fig. 3. The variation of surface roughness based on lubrication condition in milling with TiN coated WC cutting tool: a - MQL flow rate of $20 \mathrm{ml} / \mathrm{h} ; \mathrm{b}-\mathrm{MQL}$ flow rate of $40 \mathrm{ml} / \mathrm{h}$

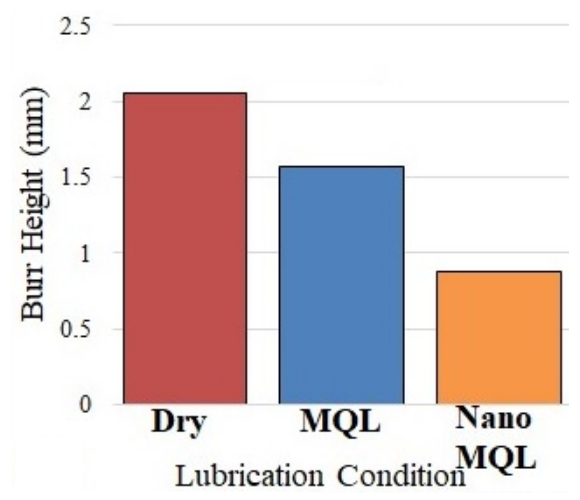

a

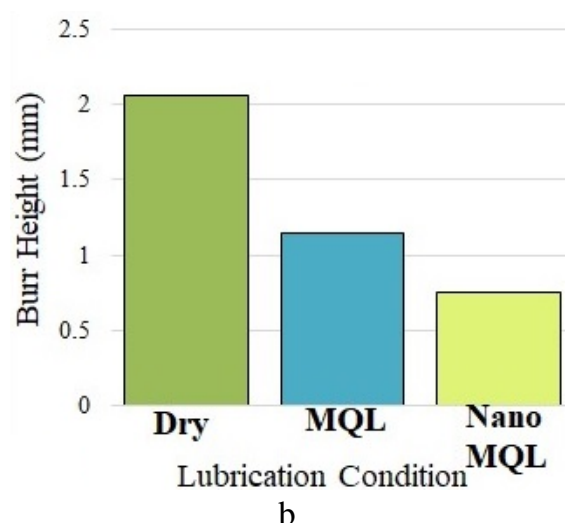

b

Fig. 4. The variation of burr height based on lubrication condition in milling with uncoated WC cutting tool: $\mathrm{a}-\mathrm{MQL}$ flow rate of $20 \mathrm{ml} / \mathrm{h} ; \mathrm{b}-\mathrm{MQL}$ flow rate of $40 \mathrm{ml} / \mathrm{h}$
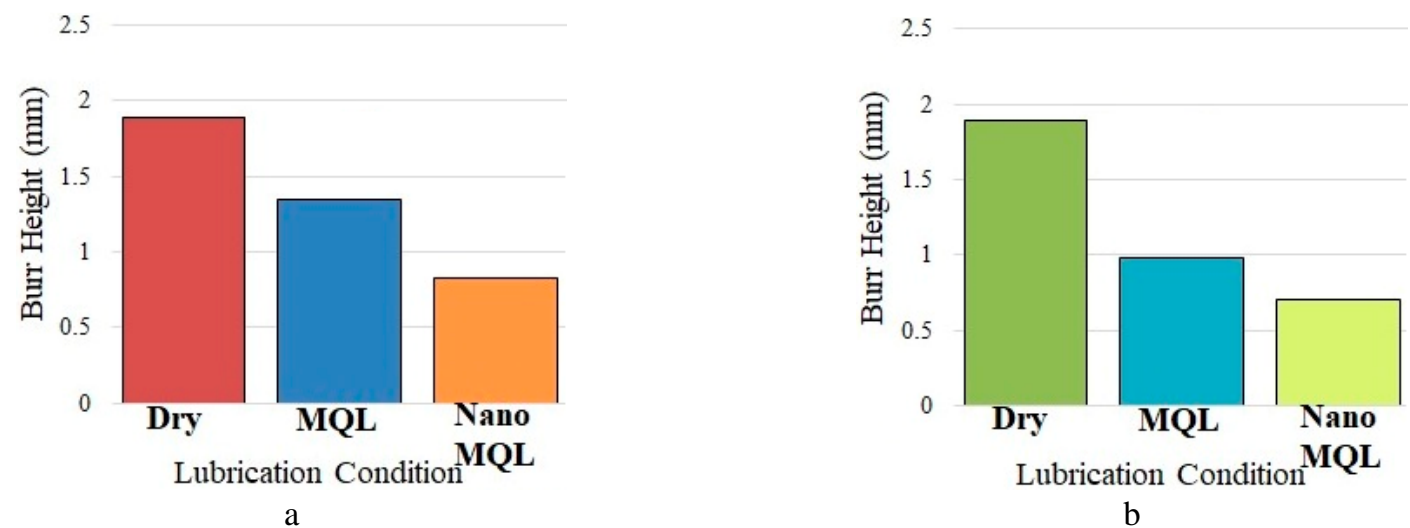

Fig. 5. The variation of burr height based on lubrication condition in milling with TiN coated WC cutting tool: a - MQL flow rate of $20 \mathrm{ml} / \mathrm{h} ; \mathrm{b}-$ MQL flow rate of $40 \mathrm{ml} / \mathrm{h}$

Depending on the burr images, nano MQL milling method gave smaller burr heights than dry and MQL milling operations as seen in Figs. 6 and 7. In milling with TiN coated WC at MQL flow rate of $20 \mathrm{ml} / \mathrm{h}$, the burr height was measured as $1.35 \mathrm{~mm}$ whereas $2.06 \mathrm{~mm}, 1.89 \mathrm{~mm}$ and $1.57 \mathrm{~mm}$ values were measured for dry milling with uncoated WC, dry milling with TiN coated WC and MQL milling with uncoated $\mathrm{WC}$ at MQL flow rate $20 \mathrm{ml} / \mathrm{h}$, respectively.

The burr heights were reduced from $1.57 \mathrm{~mm}$ to $1.15 \mathrm{~mm}$ and from $1.35 \mathrm{~mm}$ to $0.97 \mathrm{~mm}$ by increasing MQL flow rate for uncoated WC and TiN coated WC, respectively. When nano MQL method was used at MQL flow rate of $40 \mathrm{ml} / \mathrm{h}$, the burr heights were measured as $0.75 \mathrm{~mm}$ and $0.7 \mathrm{~mm}$ for uncoated WC and TiN coated WC, respectively. 


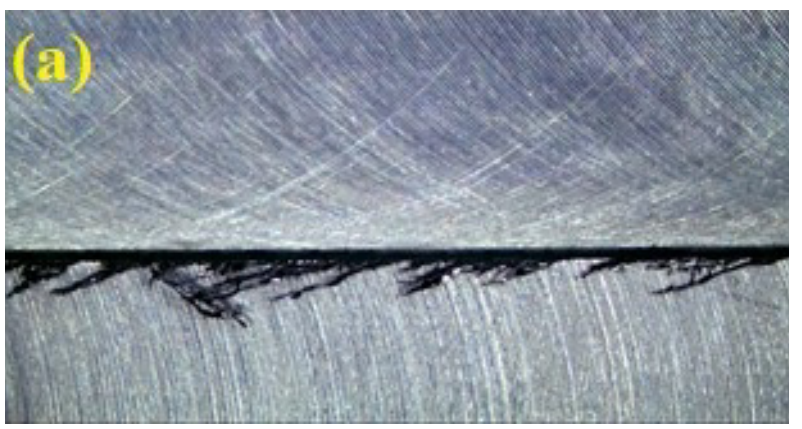

a

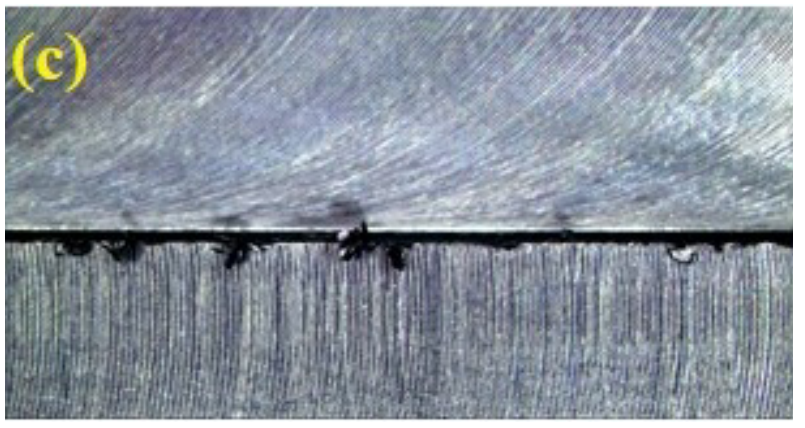

C

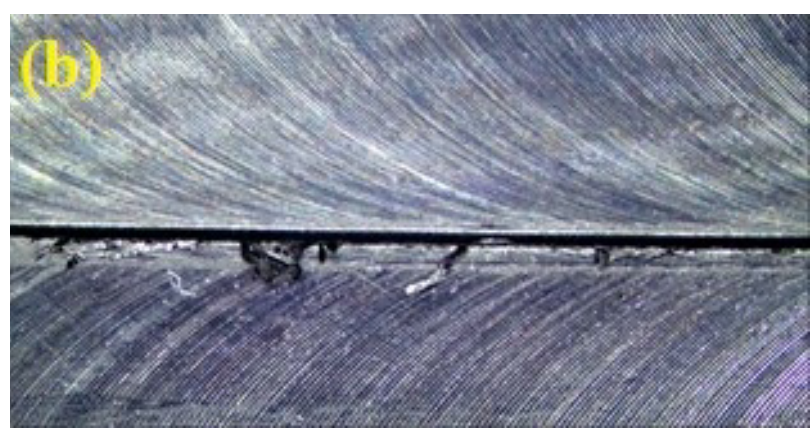

b

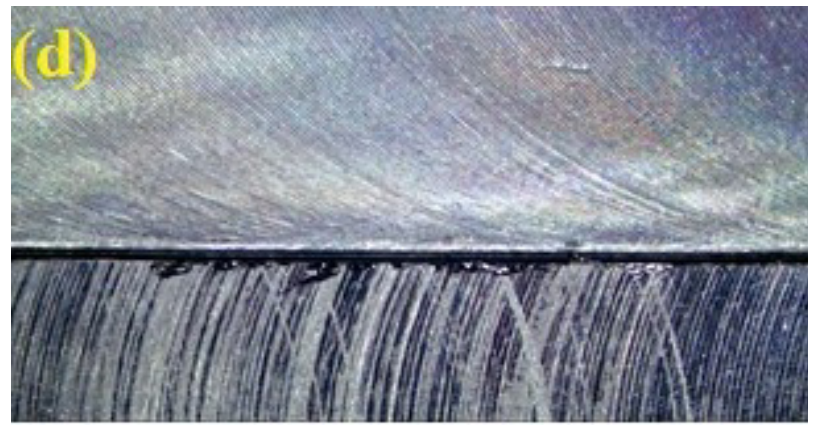

$\mathrm{d}$

Fig. 6. Burr views (7x magnification): a - dry milling with uncoated WC; b - dry milling with TiN coated WC; c-MQL milling with $20 \mathrm{ml} / \mathrm{h}$ flow rate and uncoated WC; d-MQL milling with $20 \mathrm{ml} / \mathrm{h}$ flow rate and TiN coated WC

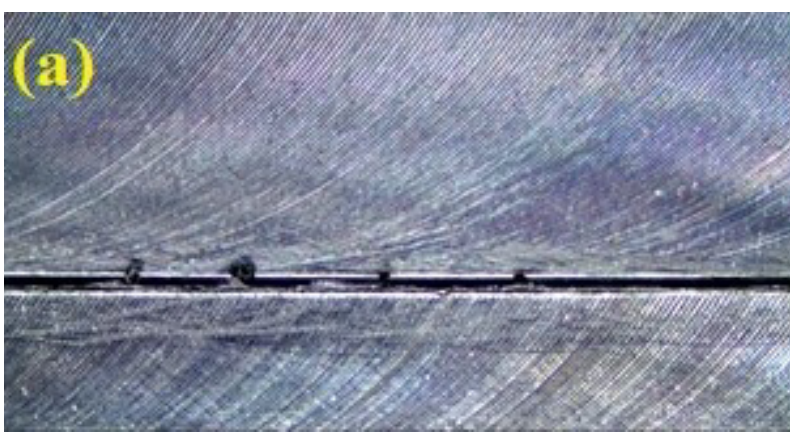

a

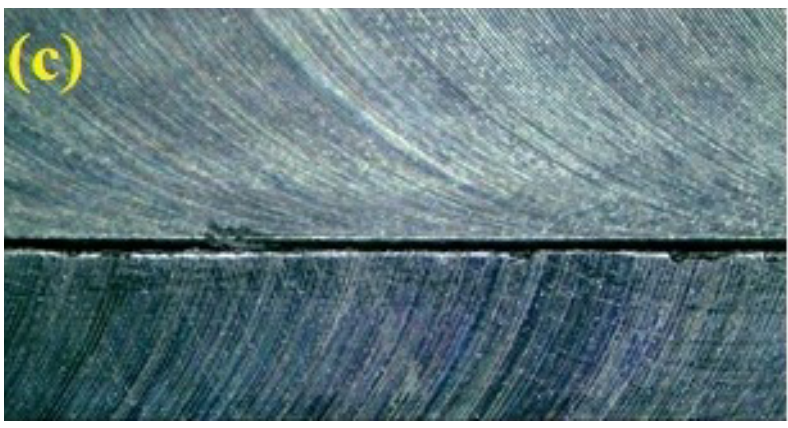

C

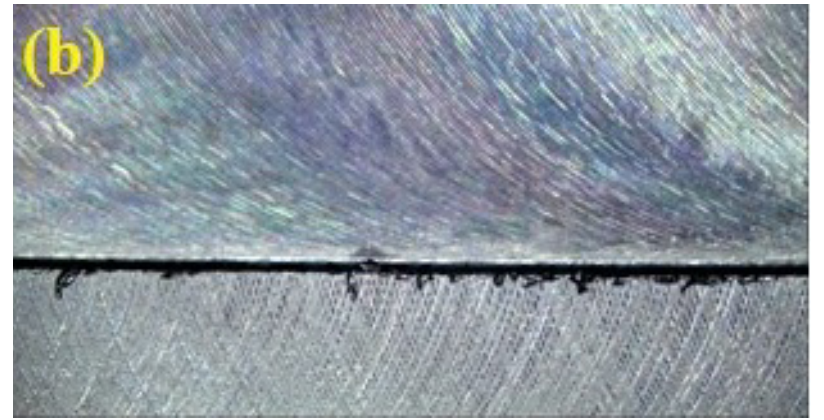

$\mathrm{b}$

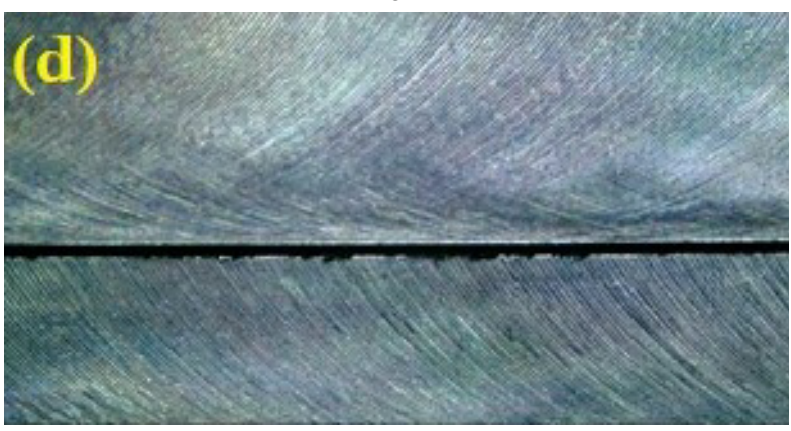

d

Fig. 7. Burr views (7x magnification): a - MQL milling with $40 \mathrm{ml} / \mathrm{h}$ flow rate and uncoated $\mathrm{WC}$; $\mathrm{b}-\mathrm{MQL}$ milling with $40 \mathrm{ml} / \mathrm{h}$ flow rate and TiN coated WC; c - Nano MQL milling with $40 \mathrm{ml} / \mathrm{h}$ flow rate and uncoated WC; $\mathrm{d}$ - Nano MQL milling with $40 \mathrm{ml} / \mathrm{h}$ flow rate and TiN coated WC

\section{Conclusions}

Based on the results, surface roughness and burr heights reduced by pulverizing the cutting fluid to the cutting zone through MQL system. In addition, an increment at MQL flow rate and also the usage of TiN coating decreased the surface roughness and burr heights. In other words, the surface quality can be 
improved by using MQL method and TiN coating. Additionally, better surface roughness and smaller burr heights were obtained under nanofluid MQL milling operations due to lubrication and heat removal characteristics of MWCNT particles. Consequently, the best surface was obtained in nano MQL milling with TiN coated WC tool at MQL flow rate of $40 \mathrm{ml} / \mathrm{h}$.

\section{References}

[1] Pooja A. Sutar, and A. J. Gujar, "Study the effect of machining parameters on surface roughness in CNC Milling of AISI 316L", International Journal of Engineering Research and Technology, vol. 10, no. 1, pp. 801-804, 2017.

[2] Y. Yao, et al., "Investigation on chip formation and surface integrity in micro end milling of maraging steel", The International Journal of Advanced Manufacturing Technology, vol. 102, pp. 1973-1984, 2019.

[3] Y. Meixia, et al., "Investigation on burrs in micro milling of stainless steel 310S", in IOP Conf. Series: Materials Science and Engineering, Singapore, August 21-23, 2017, 244012002.

[4] P. Nowak, K. Kucharska, and M. Kamiński, "Ecological and Health Effects of Lubricant Oils Emitted into the Environment", International Journal Of Environmental Research And Public Health, vol. 16, 3002, 2019.

[5] T. S. Ogedengbe1, P. Awe, and O. I. Joseph, "Comparative Analysis of Machining Stainless Steel using Soluble and Vegetable oils as Cutting Fluids", International Journal of Engineering Materials and Manufacture vol. 4, no. 1, pp. 33-40, 2019.

[6] B. Kumar, et al., "Experimental Investigations of Vegetable Oil Based Cutting Fluids with Extreme Pressure Additive in Machining of AISI 1040 Steel”, Manufacturing Science and Technology, vol. 3, no. 1, pp. 1-9, 2015.

[7] S. Ekinović, E. Begović, and A. Lušija, "MQL Machining - Oil on Water Droplet System", in Proc. of the 4th International Symposium on Sustainable Development, Ilidža, Bosnia and Herzegovina, May 25, 2013, pp. 1-8.

[8] Ch. Yakybov, R. Dzhemalyadinov, and V. Skakun, "Improving material cutting by application of natural origin oil" in MATEC Web of Conferences, Sevastopol, Republic of Crimea, September 10-14, 2018, 224(51):01130.

[9] S Debnath, M. M. Reddy, and Q. S. Yi, "Environmental friendly cutting fluids and cooling techniques in machining: a review", Journal of Cleaner Production, vol. 83, pp. 33-47, 2014.

[10] J. Z. Zang, P. N. Rao, and M. Eckman, "Experimental evaluation of a bio-based cutting fluid using multiple machining characteristics", International Journal of Modern Engineering, vol. 12, pp. 35-44, 2012.

[11] M. Hadi and R. Atefi, "Effect of minimum quantity lubrication with gamma-Al2O3 nanoparticles on surface roughness in milling AISI D3 steel”, Indian Journal of Science and Technology, vol. 8, no. 3, pp. 296-300, 2015. 